\title{
Management Skill to Successful Make in an Extra-Marital Affair: Rare Chance to Meet Fact File Study of Transformed in Pharmacy Colleges in Formerly Pune University
}

\author{
Rahul H* \\ Fellow Indian Council of Medical Research, India
}

*Corresponding author: Rahul Hajare, Fellow Indian Council of Medical Research, India, Email: rahulhajare17@gmail.com

\section{Opinion \\ Volume 3 Issue 2}

Received Date: July 26, 2020

Published Date: August 18, 2020

DOI: $10.23880 /$ aabsc- 16000150

\section{Abstract}

A woman who sleeps with a man she just met signals that she has low self-esteem or that she is actually only using him for sex.

\section{Executive Summary}

The study, led by the University of Pune, found that more than half of young out land lady reported problems with extra maternal sexual affair function, with the probability of reporting sexual approach increasing over time. The study discovered that two years after their initial fewer land lady out diagnosis, nearly 53 percent of young adults 18 to 39 years old still reported some degree of affected common mistake in extra maternal affair.

\section{Introduction}

It has never been easier or more acceptable to have an extramarital relationship. People believe that an extramarital relationship can make life exhilarating and even make one closer to their spouse. In the survey, couples in an extra marital relationship reported greater intimacy when they had sex with their spouses. Others love the thrill that accompanies seduction and seducing outside marriage. While some people may want to believe that extramarital relationships give them everything they want, others people make mistakes they regret. Realistically most men, when given a chance, would enthusiastically commit infidelity. The fairer sex is far choosier when it comes to selecting sexual partners. For this reason, a woman who decides to enter into an extramarital relationship may search for a partner on a dating website. After choosing to have an extramarital affair should she pick the wrong man, it could lead to issues and create trouble in her marriage. Facebook is haunted by single and married men who are looking for women. To achieve their goal, they will pretend to be everything they are not. They will lie about their age, income, qualifications, achievements, background, career and anything else to charm a married woman. A woman who falls for their routine may find that instead of a thrilling extramarital fling, she's trapped in a tumultuous relationship. Like on Facebook, men prowl bars and clubs in search of women as well. Having an extramarital relationship with a man one meets in a bar is a mistake. Most eligible men are unlikely to approach women in bars and clubs. Those who patronise such places to search for women may have baggage or serious emotional issues. While dancing with an unknown man in such locations may still be okay, taking him home for the night ought to be avoided. For a woman, the ideal partner to have an extramarital affair with is one who is married, ditto for men.

\section{Summary}

A married man or woman has to be just as discrete about an affair as the person they are cheating with. Both know full well what they are committing to before they enter into an extramarital relationship. Both parties recognise the rules before they have an affair, so there are no unexpected surprises or expectations that aren't unmet. Choosing the wrong partner can lead to unexpected expectations and troubles. This is a serious no-no. Even if you find someone adorable, don't fall in love immediately and complicate things. An extra-marital relationship can be a fun, harmless fling; don't expect it to be anything more significant. When 
Annals of Advanced Biomedical Sciences

a woman has decided she wants to commit infidelity, she becomes eager to take the first step. Women are choosier about whom they sleep with. Still, sometimes even a prudent woman may throw caution to the wind and sleep with the first seemingly eligible man she meets. This is fraught with trouble as sleeping with someone hastily is recipe for trouble. Every single woman knows that having sex on the first date automatically sends the wrong signals to her sexual partner. Same goes in extramarital relationships. A woman who sleeps with a man she just met signals that she has low self-esteem or that she is actually only using him for sex. Sleeping on the first meeting isn't romantic at all. Exchanging little gifts and jewels is a significant turn on in any relationship. But when a partner demands substantial sums of money, it usually leads to trouble. An extra marital relationship is not a monetary investment or business transaction. Needless to say, children who learn that their parent or parents are committing infidelity usually suffer significant trauma. Even if a spouse knows their partner is in an extramarital relationship, the children in the marriage should not. An extra-marital relationship is still considered a taboo in Indian society. Getting caught can totally dampen the trip of an extramarital relationship. It not only wrecks your marriage, but also portrays you in bad light leading to trust issues and other insecurities.

\section{Conclusion}

Black and white can desire for sex.

\section{Acknowledgment}

I acknowledge for this important work with Honorable Respected Dr. R.S.Paranjape. World Renowned Scientist \& Retired Director \& Scientist 'G High Grade Institute National AIDS Research Institute Pune. This has inspired \& captured the imagination and attention of across the research and pure service.

\section{References}

1. Rahul H (2018) Safe Sex: The True Principal Health? Medical Research and Clinical Case Reports 1: 79-81.

2. Rahul H (2018) Safe sex: the train your mind (revise). Gen Med Open 2(2): 1-2.

3. Rahul H (2018) Indian Women, Trauma and Hydroxyl Drugs Dependency: Connections and Disconnections in Heart Disease for Women. Int J Curr Innov Adv Res 1(2): $1-2$.

4. Rahul H (2018) Extra-Marital Affair Can Lead Trauma and Connections in Higher Risk for Heart Disease in Indian Women. Drug Des Int Prop Int J 2(1). 